\title{
Baicalein inhibits the invasion of human cervical cancer cells by inhibiting the hedgehog/Gli signaling pathway
}

\author{
Hai Yang ${ }^{1}$, Jiyi $\mathrm{Xia}^{2}$, Yan $\mathrm{Li}^{3}$, Yong $\mathrm{CaO}^{3}$, Li Tang ${ }^{3}$, Xiaolan $\mathrm{Yu}^{1 \text { * }}$ \\ ${ }^{1}$ Department of Obstetrics and Gynecology, The Affiliated Traditional Chinese Medicine Hospital of South West Medical \\ University, ${ }^{2}$ School of Medical Information and Engineering, Southwest Medical University, ${ }^{3}$ Medicine Experimental Center, The \\ Affiliated Hospital of Southwest Medical University, Luzhou, China
}

*For correspondence: Email: yuxiaolanwork@163.com; Tel: +86-0830-3161913

Sent for review: 29 July 2019

Revised accepted: 21 December 2019

\begin{abstract}
Purpose: To identify the role of baicalein in human cervical cancer and to determine whether baicalein treatment affects hedgehog/Gli signaling pathway.

Methods: Cell proliferation was evaluated by MTT(3-(4,5-dimethylthiazol-2-yl)-2,5-diphenyltetrazolium bromide) and colony formation assays. Cell death rate was assessed by Pl-staining and FACS assay. Furthermore, cell invasion was assessed by Transwell assay while the levels of the key proteins were measured by western blotting analysis.

Results: Baicalein suppressed the viability and proliferation of HeLa cells. The colony formation ability and relative migration rate were significantly decreased in the HeLa cells treated with $50 \mu \mathrm{M}$ baicalein. Furthermore, the levels of Shh, Gli1, MMP-9, and VEGF declined significantly in baicalein-treated cells. Conclusion: The results demonstrate that baicalein inhibits the growth and invasiveness of cervical cancer cells partly by suppressing the activation of hedgehog/Gli signaling pathway in a concentrationdependent manner.
\end{abstract}

Keywords: Cervical cancer, baicalein, hedgehog/Gli pathway, MMP-9

\begin{abstract}
This is an Open Access article that uses a fund-ing model which does not charge readers or their institutions for access and distributed under the terms of the Creative Commons Attribution License (http://creativecommons.org/licenses/by/4.0) and the Budapest Open Access Initiative (http://www.budapestopenaccessinitiative.org/read), which permit unrestricted use, distribution, and
\end{abstract} reproduction in any medium, provided the original work is properly credited.

Tropical Journal of Pharmaceutical Research is indexed by Science Citation Index (SciSearch), Scopus, International Pharmaceutical Abstract, Chemical Abstracts, Embase, Index Copernicus, EBSCO, African Index Medicus, JournalSeek, Journal Citation Reports/Science Edition, Directory of Open Access Journals (DOAJ), African Journal Online, Bioline International, Open-J-Gate and Pharmacy Abstracts

\section{INTRODUCTION}

Cervical cancer occurs commonly worldwide with the age of onset of approximately $30-35$ years [1]. However, recently, cervical cancer has been found to develop in the younger population. Cervical cancer in humans normally invades other organs, such as the lungs, breast, liver, and bones [2]. Metastasis of cancer cells takes place usually by direct or lymphatic spread, while hematogenous metastasis is less likely to be seen.
Surgical treatment and radiotherapy, supplemented with chemotherapy, are the major therapeutic options for the treatment of cervical cancer [3]. Till now, the causes and molecular mechanisms of human cervical tumor invasion and metastasis are still unclear. As the biological characteristics of invasive cervical cancer seriously affect the efficacy of treatment, it is required to elucidate the mechanism of human cervical cancer which may be helpful and beneficial to treat this cancer. 
Baicalein is one of the principal components present in the roots of Scutellariae radix [4]. It is reported that baicalein possesses antiinflammatory activities (5), while in cervical cancer, it has been found that mitochondrial and the death receptor pathways contribute to the inhibitory effects of baicalein [6]. Furthermore, a research group has reported that baicalein inhibits human cervical cancer by inhibiting cell migration and inducing cell apoptosis [7-10]. However, the molecular mechanism of baicalein involved in the invasion and migration of human cervical cancer has not been clarified until now.

Hedgehog/Gli pathway is a conserved signaling pathway regulating various physiological processes, including cell proliferation, differentiation, and epithelial-mesenchymal transition [14]. Now, it has been reported that the abnormal activation of hedgehog/Gli pathway contributes to the metastasis of human cancers, for example, the expression of CD24 was the target gene of the hedgehog/Gli pathway which downregulated the CD24 level to suppress the progression of ovarian cancer [12].

In invasive hepatocellular carcinoma, the activation of MMP-2 and MMP-9 contributes to cell invasiveness in HepG2 related to Shh signaling [13]. Till now, it has been reported that the hedgehog/Gli pathway regulates cervical cancer cell proliferation, survival, and migration [14-15]. Silencing the expression of the Shh gene efficiently inhibits EMT and the proliferation of human cervical cancer cells [16]. MicroRNA-129$5 p$ [17] and miR-506 [18] also inhibits Gli3 in the hedgehog pathway and regulates the progression of human cervical cancer.

However, it has not been reported whether treatment with baicalein in cervical cancer inhibits the activation of the hedgehog/Gli signaling pathway.

\section{EXPERIMENTAL}

\section{Cell lines and agents}

DMEM and FBS were obtained from Gibco BRL. Baicalein was purchased from Sigma-Aldrich Biotechnology and the purity was $>98.0 \%$ (cat. no. 465119). Baicalein was diluted with DMSO. MTT reagent (cat. no. 88417) was purchased from Sigma Inc. (Sigma, Saint Louis, MO).

\section{MTT assay}

The human cervical cancer cells $\left(2 \times 10^{3}\right.$ cells/well) were treated with baicalein for an indicated time and diluted at a final concentration of $0.4,2,10$, and $50 \mu \mathrm{M}$. Before the test, $10 \mu \mathrm{L}$ of MTT was injected to each well and cultured for another $4 \mathrm{~h}$. Finally, DMSO was used to resolve the crystal.

\section{FACS assay}

The cell death rate was determined by $\mathrm{PI}$ staining with FACS assay. Briefly, baicalein was diluted to 2,10 , and $50 \mu \mathrm{M}$ and was used to treat the cells for $24 \mathrm{~h}$. Then, $8 \times 10^{6}$ cells were resuspended in $800 \mu \mathrm{L}$ of PBS containing $10 \mu \mathrm{L}$ of PI. The suspension was kept to avoid light for $5 \mathrm{~min}$ at room temperature. The specimens were tested using flow cytometry (Millipore Corporation, Billerica, MA, USA).

\section{Colony-forming assay}

The HeLa cells were cultured and plated on 6well plates. The cells were then treated with baicalein for 14 days. The concentrations of baicalein were diluted from $50 \mu \mathrm{M}$, respectively. The colonies ( $>50$ cells) were recorded and the assay was performed twice. The colony formation rate was calculated as in Eq 1. $\mathrm{A}(\%)=$ $\mathrm{B} / \mathrm{C} \times 100 \%$ (A: colony formation rate; $\mathrm{B}$ : number of colonies; and C: number of inoculated cells).

\section{Transwell assay}

The HeLa cells $\left(3 \times 10^{4}\right)$ were plated on the matrigel of a small chamber. The concentration of baicalein was 2,10 , and $50 \mu \mathrm{M}$, respectively. After $24 \mathrm{~h}$, the invasive HeLa cells present in the lower layer were stained with Trypan blue. The cells were observed under a microscope and five fields (200x) were counted randomly in each well to obtain an average. This process was repeated thrice.

\section{Western blotting analysis}

Shh, Smo, Gli1, MMP-9, and VEGF were estimated by western blotting. The antibodies used were: Shh antibody (cat. no. 435800; antimouse monoclonal antibody; ThermoFisher Scientific Corporation), Smo antibody (E-5) [cat. no. sc-166685; mouse-derived monoclonal antibody $(200 \mu \mathrm{g} / \mathrm{mL})$; Abcam Corporation], antiGli1 antibody (cat. no. ab151796; rabbit polyclonal antibody; Abcam Corporation), MMP-9 Antibody (cat. no. 3852; Cell Signaling Technology Corporation), and VEGF antibody (C-1) (cat no. sc-7269; Santa Cruz Biotechnology Corporation). The bands were developed by ECL reagent. Each band was scanned and quantified using optical densitometry (Image $\mathrm{J}, \mathrm{NIH}$ ). 


\section{Statistical analysis}

The results were analyzed by independent samples $t$-test. The data are shown as mean \pm SD.

\section{RESULTS}

\section{Baicalein inhibited the viability of HeLa cells}

Different concentrations of baicalin were used to treat the HeLa cells. The chemical structure of baicalein is shown in Figure $1 \mathrm{~A}$. As shown in Figure $1 \mathrm{~B}$, the inhibitory rate of the HeLa cells was increased as the concentration of baicalein was higher $(p<0.01)$ as compared to the untreated HeLa cells. Moreover, the concentrations of baicalein were diluted to $0.4,2$, 10 , and $50 \mu \mathrm{M}$, respectively. As shown in Figure $1 \mathrm{C}$, the inhibitory rate in the baicalein group was greatly increased. The data suggested that baicalein suppressed cell growth in a time- and concentration-dependent manner. Additionally, baicalein induced the death of HeLa cells as detected by FACS. As shown in Figure 2, the death rates in the 10 and $50 \mu \mathrm{M}$ of the compound-treated groups were much higher than that in the control group $(p<0.01$ as compared to the untreated cells). The data showed that baicalein had efficient antitumor activity in human cervical cancer cells.

\section{Baicalein inhibited the colony-forming capacity of the HeLa cells}

Formation assay was performed and the results showed that baicalein inhibited the colony formation efficiency of the HeLa cells (Figure 3). Moreover, as the concentration of baicalein increased (especially > $10 \mu \mathrm{M}$ ), the colony formation ability was greatly decreased in a concentration-dependent manner.

\section{Baicalein inhibited the invasion of HeLa cells}

The effects of baicalein on the in vitro cell invasion of the HeLa cells were tested by transwell assay. In Figure 4, the invasion ability was decreased as the concentration of baicalein was increased. The data revealed that the relative cell migration was significantly decreased at a baicalein concentration of $50 \mu \mathrm{M}$ for $24 \mathrm{~h}$ as compared to that in the untreated controls $(p<$ $0.01)$.

\section{Baicalein inhibited the activation of hedgehog/Gli1 pathway}

Next, we examined whether treatment with baicalein inhibited the expression of the
hedgehog/Gli pathway in the HeLa cells. Cyclopamine was used as the control to suppress hedgehog/Gli signaling in the HeLa cells $(10 \mu \mathrm{M})$. As shown in Figure 5, the Smo expression was decreased but the level of Shh was not changed in the HeLa cells. Furthermore, the western blotting analysis showed that with a higher concentration of baicalein, the levels of Shh and Gli1 were decreased in the HeLa cells, although the Smo expression was not affected. Importantly, downstream targeted gene expression was also detected in the baicalein treated HeLa cells. The data demonstrated that MMP-9 and VEGF were significantly decreased in the baicalein group. The data demonstrated that baicalein inhibited the invasion of HeLa partly by suppressing the activation of the hedgehog/Gli signaling pathway.

A<smiles>O=c1cc(-c2ccccc2)oc2cc(O)c(O)c(O)c12</smiles>

B

HeLa

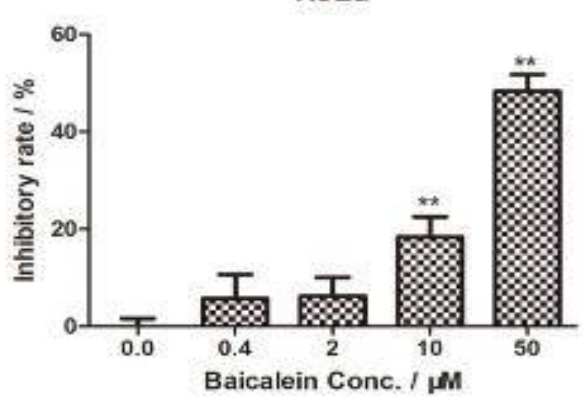

C

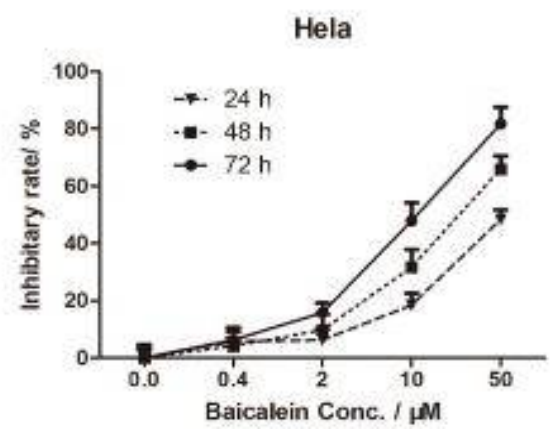

Figure 1: Baicalein inhibited the cell growth of HeLa cells. A. Chemical structure of baicalein. B. HeLa cells $\left(2 \times 10^{3} /\right.$ well) were plated on a 96 -well plate. Eight hours later, the HeLa cells were treated with baicalein for $24 \mathrm{~h} ;{ }^{* *} p<0.01$. C. The HeLa cells $\left(1 \times 10^{3} /\right.$ well $)$ were cultured for $8 \mathrm{~h}$. Baicalein concentrations were $0.4,2,10$, and $50 \mu \mathrm{M}$

Trop J Pharm Res, January 2020; 19(1): 117 

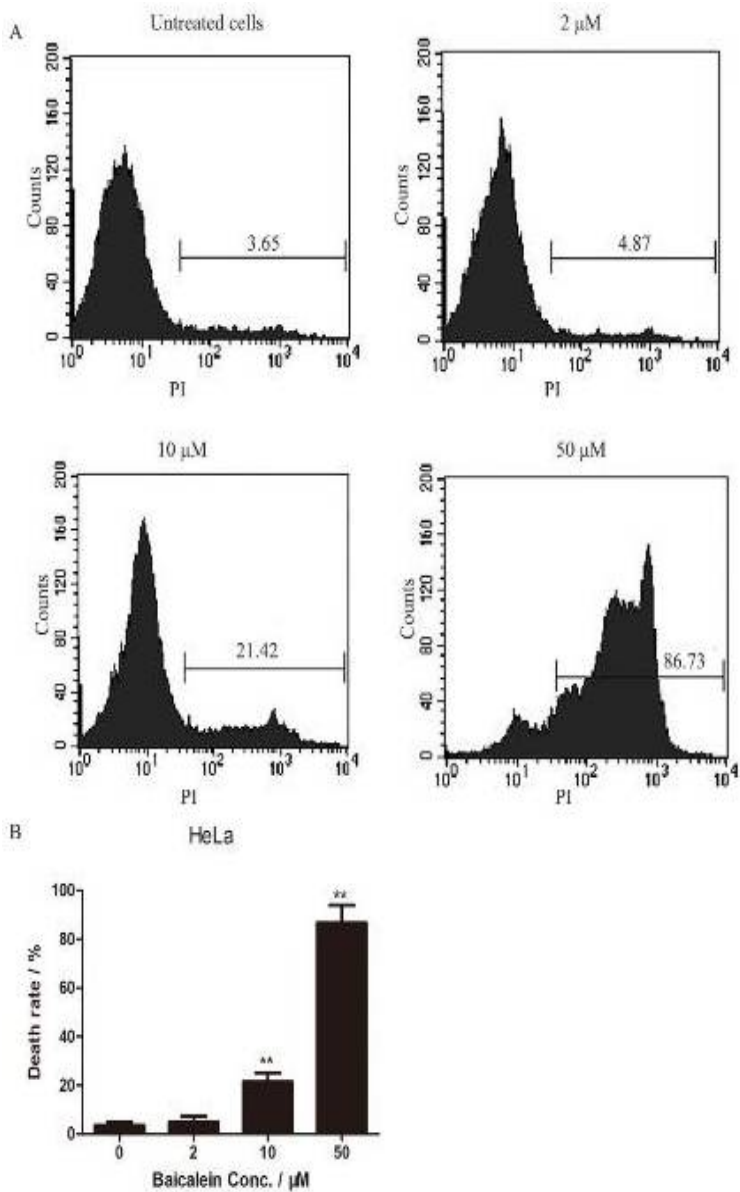

Figure 2: $(A)$ Baicalein promoted cell death. $(B)$ The death rate of HeLa cells is shown in the histogram; ${ }^{* *} p$ $<0.01$ as compared to $0 \mathrm{uM}$ of baicalein
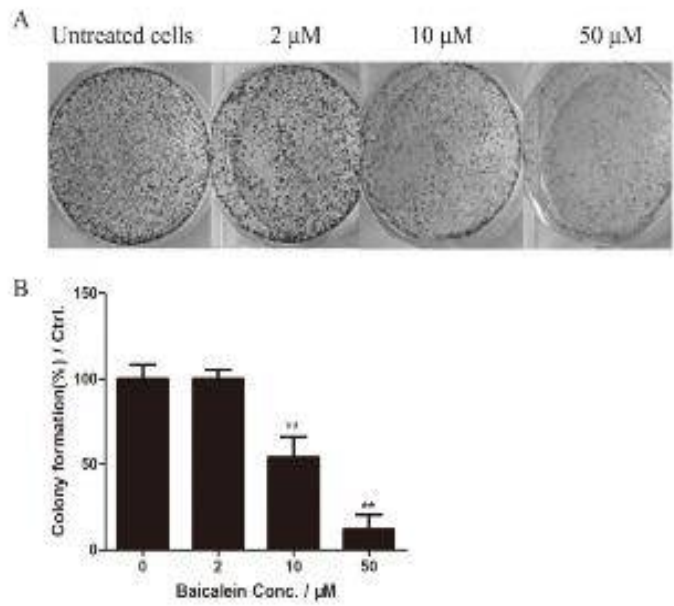

Figure 3: Baicalein inhibited colony formation. A. The Hela cells were plated on a 6-well plate (100 cells/well). Twenty-four hours later, the cells were treated with different concentrations of baicalein and cultured for 14 days. The colonies are shown here. B. The colony formation efficiency is shown in the histogram; ${ }^{* *} p<0.01$ as compared to the untreated group
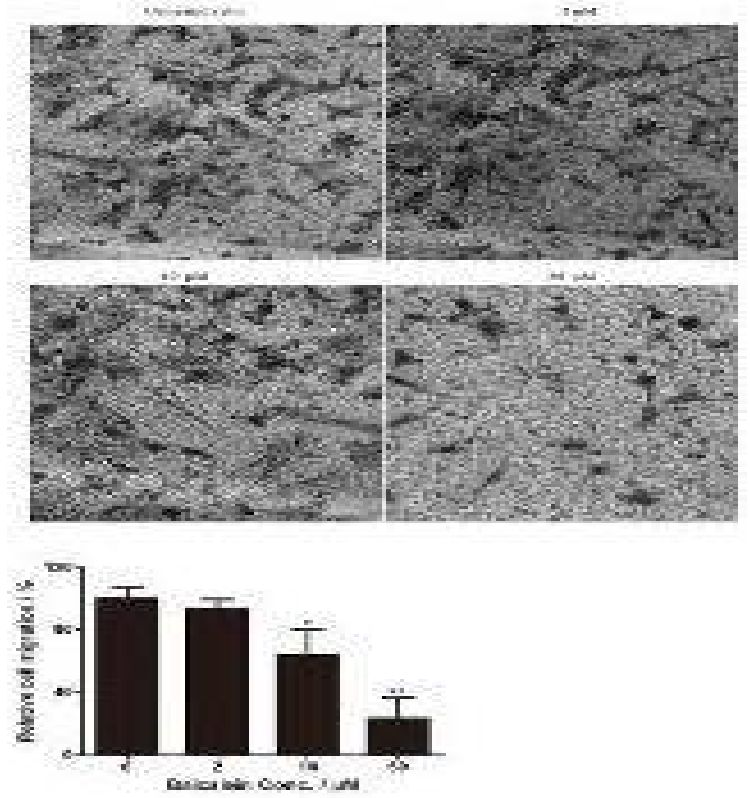

Figure 4: Baicalein inhibited the invasion of $\mathrm{HeLa}$ cells. A. Invasion assay. The HeLa cells were treated with 2,10 , and $50 \mu \mathrm{M}$ of baicalein for $24 \mathrm{~h}$ and the images of the invasive cells are shown. $B$. The relative cell migration rate is shown in the histogram. The untreated cells are used as the negative control. ${ }^{* *} p<$ 0.01 as compared to the control

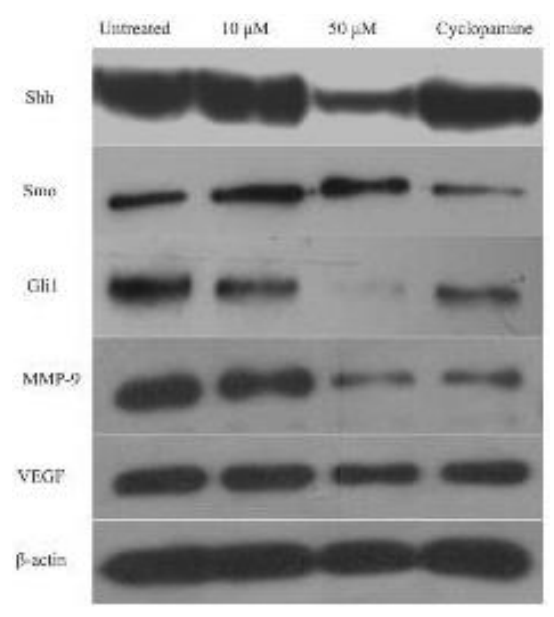

Figure 5: Effect of baicalein on the hedgehog/Gli1 signaling pathway in the HeLa cells. The levels of each factor in the untreated HeLa cells were used as the negative control

\section{DISCUSSION}

Baicalein is a flavonoid compound having various pharmacological activities. There is evidence that baicalein has anti-inflammatory and anti-tumor activities [7]. It has been known that baicalein suppresses the growth and invasion of human cervical cancer cells. Importantly, the results have shown that baicalein inhibits cell invasion by inhibiting the hedgehog/Gli pathway. Thus, it is very important to use baicalein for the 
treatment of cervical cancer, which may bring good news to patients with cervical cancer.

Firstly, the cell viability and cell death rate were determined by MTT and FACS assays, respectively. We used increasing concentrations of baicalein to treat the HeLa cells, and the colony-forming capacity of the HeLa cells was significantly decreased when treated with 10 or $50 \mu \mathrm{M}$ of baicalein for 14 days. The results showed that baicalein inhibited the proliferation of HeLa cells, which was consistent with the results of $\mathrm{Ma}$ et al. in which the authors hypothesized that baicalein inhibited the metastasis of cancer cells by reducing the level of SATB1 and Wnt/beta-catenin pathway [19]. Hedgehog/Gli signaling pathway has also been reported to contribute to cancer invasion and metastasis in various human cancers. However, whether baicalein affects the activation of hedgehog/Gli signaling has not been clarified in human cervical cancer.

Most studies have shown that baicalein inhibited the migration of cancer cells mainly by inducing cell apoptosis and cell cycle arrest [9]. Here, the anti-metastatic effects of baicalein on cervical cancer cells were explored. The underlying molecular mechanisms were also evaluated. Baicalein inhibited the activation of the hedgehog/Gli1 signaling pathway in the HeLa cells. We used cyclopamine, a special inhibitor of the hedgehog/Gli pathway, as the control compound in the experiment. Cyclopamine could bind to smoothened (Smo) protein and suppress the activity of hedgehog/Gli signaling. The key proteins that were detected in the hedgehog/Gli pathway were Shh, Smo, Gli1, MMP-9, and VEGF.

The level of matrix MMP-9 is higher in cervical cancer [20]. In the present study, the level of MMP-9 was significantly downregulated in the HeLa cells, suggesting that MMP-9 might be the downstream target protein of the hedgehog/Gli signaling pathway. Additionally, in the rectal cancer tissues, VEGF was highly expressed and positively associated with tumor invasion depth and lymph node metastasis [21]. A higher VEGF level was shown to enhance the migration and invasion ability of the pancreatic cancer cells [22]. In our study, we found that baicalein treatment inhibited the invasion and proliferation of HeLa cells partly by reducing the levels of VEGF in the human cervical cancer cells.

\section{CONCLUSION}

The findings of this study reveal that baicalein promotes cell death and inhibits the invasion of
HeLa cells partly by suppressing the activation of hedgehog/Gli signaling pathway. Thus, it is potentially an effective agent for the management of human cervical cancer.

\section{DECLARATIONS}

\section{Acknowledgement}

The work was supported by Shengzhou Science and Technology Bureau (Project 2014-S-35); Liangshan Prefecture Science and Technology Bureau (Project 18YYJS0041); Sichuan Provincial Administration of Traditional Chinese Medicine (Project 2018JC029); Southwest Medical University-Luzhou Chinese Medicine Hospital Joint (Project 2017-LH020).

\section{Conflict of interest}

No conflict of interest is associated with this work

\section{Authors' contribution}

We declare that this work was done by the authors named in this article and all liabilities pertaining to claims relating to the content of this article will be borne by the authors. Xiaolan Yu designed the experiment and wrote the draft of the manuscript. Hai Yang and Jiyi Xia did the experiment including MTT assay, western blotting and FACS assay. Yan Li and Yong Cao collected the data and did the statistical analysis. $\mathrm{Li}$ Tang help to write the manuscript and did the experiment of western blotting.

\section{Open Access}

This is an Open Access article that uses a funding model which does not charge readers or their institutions for access and distributed under the terms of the Creative Commons Attribution License (http://creativecommons.org/licenses/by/ 4.0) and the Budapest Open Access Initiative (http://www.budapestopenaccessinitiative.org/rea d), which permit unrestricted use, distribution, and reproduction in any medium, provided the original work is properly credited.

\section{REFERENCES}

1. Mahmoodi P, Fani M, Rezayi M, Avan A, Pasdar Z, Karimi E, Amiri IS, Ghayour-Mobarhan M. Early detection of cervical cancer based on high-risk HPV DNA-based genosensors: A systematic review. Biofactors 2018;

2. Mangla A, Agarwal N, Saei Hamedani F, Liu J, Gupta S, Mullane MR. Metastasis of cervical cancer to breast: $A$ 
case report and review of literature. Gynecol Oncol Rep 2017; 21: 48-52.

3. Marchetti C, Manci N, Pernice M, Di Tucci C, Carraro C, Burratti M, Giorgini M, Benedetti Panici P. Multiple Bulky Lymph Nodal Metastasis in Microinvasive Cervical Cancer: A Case Report and Literature Review. Case Rep Oncol 2010; 3: 176-181.

4. Tuan PA, Kim YS, Kim Y, Thwe AA, Li X, Park CH, Lee $S Y$, Park SU. Molecular characterization of flavonoid biosynthetic genes and accumulation of baicalin, baicalein, and wogonin in plant and hairy root of Scutellaria lateriflora. Saudi J Biol Sci 2018; 25: 16391647.

5. Oo A, Teoh BT, Sam SS, Bakar SA, Zandi K. Baicalein and baicalin as Zika virus inhibitors. Arch Virol 2018;

6. Peng $Y$, Guo C, Yang Y, Li F, Zhang Y, Jiang B, Li Q. Baicalein induces apoptosis of human cervical cancer HeLa cells in vitro. Mol Med Rep 2015; 11: 2129-2134.

7. Ye $H$, Zhang $Y$, Wang $Y$, Xia J, Mao X, Yu X. The restraining effect of baicalein and U0126 on human cervical cancer cell line HeLa. Mol Med Rep 2017; 16 . 957-963.

8. Yu X, Yang Y, Li Y, Cao Y, Tang L, Chen F, Xia J. Baicalein inhibits cervical cancer progression via downregulating long noncoding RNA BDLNR and its downstream PI3K/Akt pathway. Int J Biochem Cell Biol 2018; 94: 107-118.

9. Yu X, Liu Y, Wang Y, Mao X, Zhang $Y$, Xia J. Baicalein induces cervical cancer apoptosis through the NFkappaB signaling pathway. Mol Med Rep 2018; 17: 5088-5094.

10. Wu X, Yang Z, Dang H, Peng H, Dai Z. Baicalein Inhibits the Proliferation of Cervical Cancer Cells Through the GSK3beta-Dependent Pathway. Oncol Res 2018; 26 : 645-653.

11. Benvenuto $M$, Masuelli $L$, De Smaele E, Fantini $M$, Mattera R, Cucchi D, Bonanno E, Di Stefano E, Frajese GV, Orlandi A, Screpanti I, Gulino A, Modesti A, Bei R. In vitro and in vivo inhibition of breast cancer cell growth by targeting the Hedgehog/GLI pathway with SMO (GDC-0449) or GLI (GANT-61) inhibitors. Oncotarget 2016; 7: 9250-9270.

12. Zeng $C$, Chen $T$, Zhang $Y$, Chen $Q$. Hedgehog signaling pathway regulates ovarian cancer invasion and migration via adhesion molecule CD24. J Cancer 2017; 8: 786-792.
13. Wang $Y H$, Sui $X M$, Sui $Y N$, Zhu $Q W$, Yan $K$, Wang $L S$, Wang $F$, Zhou JH. BRD4 induces cell migration and invasion in HCC cells through MMP-2 and MMP-9 activation mediated by the Sonic hedgehog signaling pathway. Oncol Lett 2015; 10: 2227-2232.

14. Xu P, Cai F, Liu X, Guo L. LKB1 suppresses proliferation and invasion of prostate cancer through hedgehog signaling pathway. Int J Clin Exp Pathol 2014; 7: 84808488.

15. Samarzija I, Beard P. Hedgehog pathway regulators influence cervical cancer cell proliferation, survival and migration. Biochem Biophys Res Commun 2012; 425: 64-69.

16. Zhang F, Ren CC, Liu L, Chen YN, Yang L, Zhang XA, Wang XM, Yu FJ. SHH gene silencing suppresses epithelial-mesenchymal transition, proliferation, invasion, and migration of cervical cancer cells by repressing the hedgehog signaling pathway. J Cell Biochem 2018; 119: 3829-3842.

17. Wang $Y F$, Yang $H Y$, Shi $X Q$, Wang $Y$. Upregulation of microRNA-129-5p inhibits cell invasion, migration and tumor angiogenesis by inhibiting ZIC2 via downregulation of the Hedgehog signaling pathway in cervical cancer. Cancer Biol Ther 2018; 1-12.

18. Wen SY, Lin Y, Yu YQ, Cao SJ, Zhang R, Yang XM, Li J, Zhang $Y L$, Wang $Y H, M a M Z$, Sun WW, Lou XL, Wang JH, Teng YC, Zhang ZG. miR-506 acts as a tumor suppressor by directly targeting the hedgehog pathway transcription factor Gli3 in human cervical cancer. Oncogene 2015; 34: 717-725.

19. Ma X, Yan W, Dai Z, Gao X, Ma Y, Xu Q, Jiang J, Zhang $S$. Baicalein suppresses metastasis of breast cancer cells by inhibiting EMT via downregulation of SATB1 and Wnt/beta-catenin pathway. Drug Des Devel Ther 2016; 10: 1419-1441.

20. Fan D, Wang $Y$, Qi $P$, Chen $Y, X u$ P, Yang $X$, Jin $X$, Tian $X$. MicroRNA-183 functions as the tumor suppressor via inhibiting cellular invasion and metastasis by targeting MMP-9 in cervical cancer. Gynecol Oncol 2016; 141 : 166-174.

21. Miao H, Ruan S, Shen M. VEGF-C in rectal cancer tissues promotes tumor invasion and metastasis. $J$ BUON 2018; 23: 42-47.

22. Sun $X$, Zhang $Y$, Li B, Yang H. MTA1 promotes the invasion and migration of pancreatic cancer cells potentially through the HIF-alpha/VEGF pathway. J Recept Signal Transduct Res 2018; 38: 352-358. 